\title{
PERAWATAN DIASTEMA AKIBAT MESIODENS PADA ANAK USIA 9 TAHUN (Laporan Kasus)
}

\author{
Suzanna Sungkar*, Heriandi Sutadi** \\ *Staf Pengajar Program Studi Kedokteran Gigi Fakultas Kedokteran Universitas Syiah Kuala \\ *Peserta PPDGS Ilmu Kedokteran Gigi Anak Fakultas Kedokteran Gigi Universitas Indonesia \\ **Departmen Ilmu Kedokteran Gigi Anak Fakultas Kedokteran Gigi Universitas Indonesia
}

\begin{abstract}
Mesiodens is a supernumerary tooth which is commonly found in the midline of the maxilla between the two central incisors. Supernumerary teeth are more often found in permanent than in primary teeth. Mesiodens may cause clinical disorders, such as delayed eruption or malposition of adjacent permanent teeth. Both conditions frequently result in an irregularity of developing occlusion. This paper will report mesiodens in a 9 years old girl who complained of space in the maxilla anterior teeth with anterior crossbite. The treatment included extraction of mesiodens with closing diastema and correction of the anterior crossbite with a simple orthodontic appliance. It was concluded that treatment is important to prepare space for eruption of maxillary lateral incisors, correcting diastema in the region of anterior maxilla and repairing anterior crossbite.
\end{abstract}

Key words: Supernumerary; mesiodens; anterior crossbite; extraction; orthodontic treatment.

\section{Pendahuluan}

Gigi-lebih atau hiperdonsia merupakan kelebihan satu atau lebih elemen gigi dari jumlah normal. ${ }^{1-4}$ Kelainan ini dapat terjadi pada gigi sulung maupun gigi tetap, erupsi atau impaksi, tunggal atau multipel, unilateral atau bilateral, dan pada satu atau kedua rahang. ${ }^{5-7}$ Gigi-lebih paling sering ditemukan sebagai suatu anomali yang berdiri sendiri. ${ }^{2}$ Gigilebih yang multipel biasanya ditemukan bersama dengan sindrom lain, seperti celah langit-langit dan celah bibir, kleidokranial displasia, sindrom Down, dan sindrom Gardner. ${ }^{2-5,8}$ Banyak teori yang men jelaskan etiologi keadaan ini, tetapi etiologi yang pasti belum jelas. ${ }^{1,4,7,9}$ Beberapa teori di antaranya adalah teori atavisme (phylogenetic reversion) yaitu berulang-nya sejarah nenek moyang yang dulunya memiliki tiga insisif, tetapi teori ini ditentang banyak ahli. ${ }^{1,9-11}$ Teori lainnya adalah teori dikotomi yang menyatakan bahwa gigi-lebih terjadi dari pembelahan satu benih gigi menjadi dua gigi. ${ }^{1,4,7,11,12}$ Teori yang banyak diterima adalah teori hiperaktivitas, yakni sisa-sisa lamina dentalis atau perluasan ke palatal lamina dentalis yang aktif diinduksi membentuk benih gigi tambahan. $4,7,10,11,13,14$

Faktor herediter juga berperan penting, terlihat dari seringnya ditemukan kaitan antara pasien gigi lebih dengan hubungan keluarga. ${ }^{1,4,7,14,15}$ Beberapa pola pewarisan yang dikemukakan dalam literatur yaitu dominan autosom dengan penetrasi tidak

\footnotetext{
*Alamat korespondensi: Program Studi Kedokteran Gigi Fakultas Kedokteran Universitas Syiah Kuala. e-mail: Suzanna_Sungkar@yahoo.com
} 
sempurna dan pola pewarisan $x$-link, dengan laki-laki dua kali lebih sering terkena dibandingkan perempuan. ${ }^{1,4,11}$

Gigi-lebih diklasifikasikan berdasarkan bentuk dan lokasi. ${ }^{10}$ Menurut bentuknya, gigi-lebih diklasifikasikan menjadi konis, tuberkel, supplemental, dan bentuk yang menyerupai odontoma. Sebagian besar gigi-lebih berbentuk konis atau tuberkel. Gigi sulung biasanya berbentuk normal atau konis, sedangkan gigi tetap mempunyai variasi bentuk yakni, konis, tuberkel, supplemental, dan bentuk yang menyerupai odontoma. ${ }^{8,14}$ Berdasarkan lokasinya gigi-lebih dikategorikan menjadi mesiodens, paramolar, dan disto-molar. Paramolar adalah gigi-lebih yang berlokasi di daerah molar, sedangkan distomolar berlokasi di distal gigi molar tiga. ${ }^{1}$ Mesiodens merupakan gigi-lebih yang paling sering ditemukan, lokasinya pada daerah garis tengah rahang atas. ${ }^{2,3,5,6,12}$

Mesiodens dapat dijumpai pada gigi sulung maupun gigi tetap, tetapi lebih sering pada gigi tetap. 2,5,10,13 Insidens mesiodens yang terjadi pada gigi tetap bervariasi antara $0,15-3,8 \%$ dan pada gigi sulung $0-1,9 \%{ }^{13}$ Mesiodens pada gigi tetap anak laki-laki dua kali lebih sering daripada anak perempuan. $^{10,13}$ Menurut bentuknya ada tiga tipe mesiodens; yang paling umum adalah bentuk konis, dapat juga ditemukan bentuk tuberkel dan supplemental. ${ }^{7,11,13,14}$ Mesiodens paling sering ditemukan tunggal tetapi dapat juga berpasangan. ${ }^{7}$

Diagnosis dini mesiodens didasarkan pada pemeriksaan klinis dan radiografis. ${ }^{2,4,7,16}$ Pemeriksaan radiografis yang dilakukan meliputi rontgen foto oklusal, periapeks, dan panoramik. Lokasi mesiodens dan adanya gigi terpendam dapat diketahui dengan pemeriksan radiografis ini. $^{2}$ Diagnosis dini ini penting untuk menentukan perawatan apa yang akan dilakukan dan kapan dilakukan sehingga memberikan hasil yang optimal dan menghindari pembedahan yang luas, perawatan ortodonsia, dan komplikasi-komplikasi yang mungkin timbul. ${ }^{2,4,17}$

Adanya mesiodens dapat diduga jika ditemukan suatu pola erupsi gigi insisif rahang atas yang tidak simetris, erupsi yang terlambat dari gigi insisif rahang atas dengan atau tanpa prolonged retention gigi-gigi insisif sulung, atau adanya gigi insisif rahang atas yang bererupsi ektopik. ${ }^{2}$ Adanya diastema sentral yang berat mengindikasikan adanya mesiodens di mesial dari akar-akar gigi insisif sentral. ${ }^{18}$

Mesiodens dapat menyebabkan masalah klinis antara lain, gigi sulung bertahan lebih lama dalam rongga mulut dan erupsi yang terlambat dari gigi tetap pengganti, penyimpangan arah erupsi gigi tetap pengganti, rotasi gigi tetap yang berdekatan, dilaserasi atau perkembangan akar yang abnormal dari gigi tetap dan terbentuknya diastema yang abnormal. ${ }^{10,15,16,18,19}$ Adanya mesiodens juga dapat menyebabkan gigi berjejal, menghalangi erupsi gigi lainnya dan gigi yang berdekatan tidak erupsi pada tempatnya. $^{13,19}$ Komplikasi lainnya yang dapat ditimbulkan adalah kista, resorbsi gigi sebelahnya, dan komplikasi lainnya yang berhubungan dengan perkembangan geligi dan oklusi anak. ${ }^{2,4,13}$ Mesiodens yang erupsi dapat menimbulkan susunan geligi yang tidak teratur dan dapat menimbulkan masalah estetika. ${ }^{16}$

Perawatan mesiodens tergantung kepada tipe, posisi, dan pengaruhnya pada gigi yang berdekatan. ${ }^{7}$ Penatalaksanaan mesiodens harus merupakan bagian dari suatu rencana perawatan yang menyeluruh dan tidak berdiri sendiri. ${ }^{4}$ Tidak semua mesiodens memerlukan perawatan. Pada mesiodens yang tidak mengganggu erupsi gigi dan tidak menyebabkan maloklusi dilakukan observasi; biasanya terjadi pada mesiodens yang berbentuk konis yang inverted. Pemeriksaan radiografi berkala sangat penting untuk mendeteksi adanya perubahan yang tidak diinginkan. $^{8}$ Jika mesiodens yang impaksi menimbulkan komplikasi, seperti erupsi ke dalam rongga hidung atau pembentukan kista, maka perawatan dilakukan dengan pengambilan mesiodens secara bedah., ${ }^{2,4}$

Mesiodens yang erupsi dan menimbulkan komplikasi, dirawat dengan melakukan pencabutan. ${ }^{20}$ Pencabutan mesiodens gigi sulung yang tidak erupsi atau mesiodens gigi tetap yang erupsi dianjurkan pada periode geligi bercampur, agar gigi inisisif tetap dapat erupsi secara normal di dalam rongga mulut. Penundaan pencabutan sampai perkembangan akar gigi-gigi insisif yang berdekatan paling sedikit dua pertiga akar, akan memberikan risiko yang lebih sedikit bagi perkembangan gigigigi insisif tetap, tetapi masih memungkinkan gigigigi insisif tetap erupsi secara spontan. Pada $75 \%$ kasus, pencabutan mesiodens selama masa geligi bercampur menghasilkan erupsi spontan dan susunan geligi yang baik. ${ }^{2}$ Jika gigi-gigi yang berdekatan tidak erupsi dalam waktu 6-12 bulan, pengambilan secara bedah dan perawatan ortodonsia mungkin dibutuhkan untuk membantu gigi-gigi tersebut erupsi. ${ }^{2,4}$ Pada beberapa kasus, perawatan ortodonsia cekat juga dibutuhkan untuk menyediakan ruangan yang cukup dalam lengkung rahang sebelum gigigigi insisif tetap erupsi dan menempati tempat yang semestinya. ${ }^{4}$ 
Setelah pencabutan mesiodens, dapat terjadi diastema anterior sedangkan gigi yang berdekatan belum erupsi karena kurangnya ruangan. Diastema anterior dapat dirawat dengan menggunakan alat ortodonsia lepasan maupun alat ortodonsia cekat. Alat cekat sederhana dalam hal ini dapat dipakai, tetapi jika bagian apeks gigi masih terbuka lebar, perawatan harus dilakukan dengan hati-hati karena kemungkinan dapat mengganggu perkembangan akar gigi tersebut. ${ }^{17}$

Alat cekat sederhana dapat berupa band yang dipasangkan pada gigi insisif, dan tube horizontal yang dilas pada permukaan labial. Tube yang digunakan berukuran 0,032 sampai 0,036 inci. Kawat round yang berukuran sama ditempatkan pada tube dan ujungnya dibengkokkan ke arah gingiva untuk mencegah kawat ke luar dan mengiritasi jaringan lunak. Kemudian ditempatkan rubber elastis yang tipis di atasnya. Kekuatan resiprokal akan mendorong bagian apeks dan mahkota gigi secara bersama-sama atau terjadi gerakan bodily. ${ }^{17}$ Pada makalah ini akan dilaporkan perawatan diastema yang disebabkan adanya mesiodens yang erupsi di antara insisif sentral, disertai adanya gigitan silang anterior pada anak perempuan usia 9 tahun.

\section{Laporan Kasus}

Seorang anak perempuan usia 9 tahun datang ke klinik IKGA-FKG UI diantar ibunya pada tanggal 3 Agustus 2005 dengan keluhan, gigi depan rahang atas jarang dan gigi sebelahnya tidak tumbuh. Keadaan umum pasien baik. Proses persalinan normal. Pada pemeriksaan ekstra oral tidak ada kelainan.

Pada pemeriksaan intra oral dijumpai adanya mesiodens yang sudah erupsi di antara 11 dan 21 (Gambar 1). Selain itu dijumpai juga 53, 63, 73, 83 berbentuk peg shape dan gigi 72 dan 82 persistensi disertai kegoyangan derajat dua. Status oklusi klas I Angle disertai gigitan silang anterior antara 11 terhadap 42 dan 41, dan antara 21 terhadap 32 dan 73. Higiene oral buruk dengan indeks plak 2,33. Pemeriksaan radiografik menunjukkan adanya mesiodens di mesial 11 dan 21 (Gambar 2).

Diagnosis keluhan utama adalah adanya mesiodens berbentuk konis yang erupsi di regio 11 dan 12 . Diagnosis keadaan rongga mulut lainnya, kebersihan mulut buruk, 72 dan 82 persistensi disertai kegoyangan derajat dua, 64, 74, 84 karies dentin, 55 karies email, 36, 46 pit dan fisur dalam, maloklusi klas I tipe 3. Rencana perawatan adalah ekstraksi mesiodens dan penutupan ruangan antara 11 dan 21 dengan perawatan ortodonsia sederhana, selanjutnya setelah perawatan geligi lainnya selesai, dilakukan perawatan ortodonsia lepasan untuk mengoreksi gigitan silang anterior.

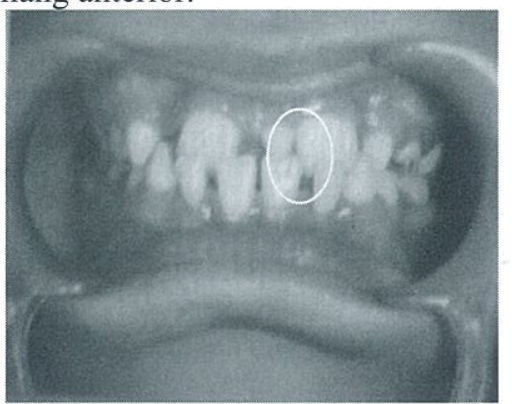

Gambar 1. Gambaran intraoral pasien tanggal 3 Agustus 2005. Terlihat adanya mesiodens

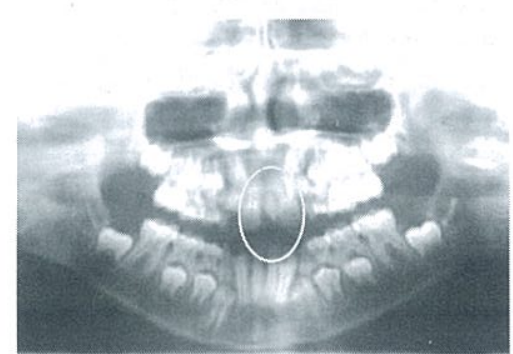

Gambar 2. Gambaran rontgen foto panoramik pasien tanggal 3 Agustus 2005

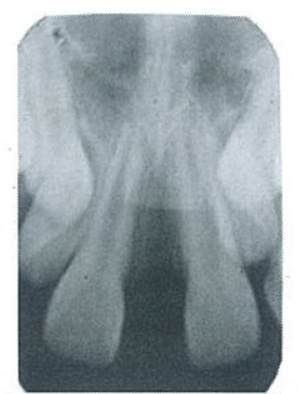

Gambar 3. Gambaran foto dental regio 11 dan 21

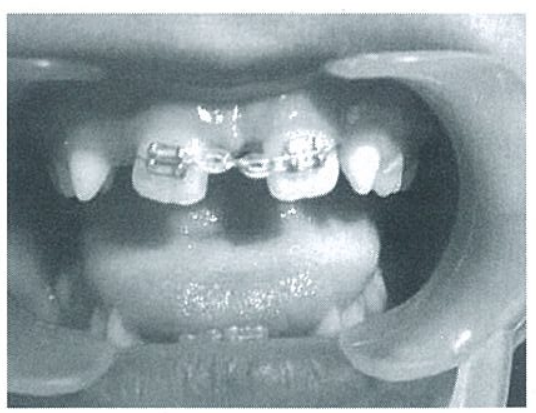

Gambar 4. Gambaran intraoral pasien pada pada tanggal 30 September 2005. Dilakukan pemasangan braket pada gigi insisif sentral dan rubber elastis dengan kekuatan ringan. 
Sebelum dilakukan pemasangan alat ortodonsia cekat, dilakukan rontgen foto dental untuk melihat perkembangan akar 11 dan 21. Pemeriksaan radiografik menunjukkan perkembangan akar 11 dan 21 mencapai $1 / 3$ apikal dan belum menutup sempurna (Gambar 3). Tanggal 30 September 2005 dilakukan pemasangan braket pada 11 dan 21, arch wire SS 0,16, dan dilakukan pemasangan rubber elastis dengan kekuatan ringan (Gambar 4).

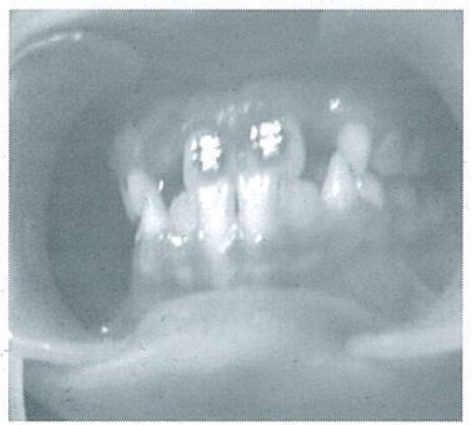

Gambar 5. Gambaran intra oral pasien pada kontrol tanggal 4 Januari 2006. Terlihat diastema sudah terkoreksi

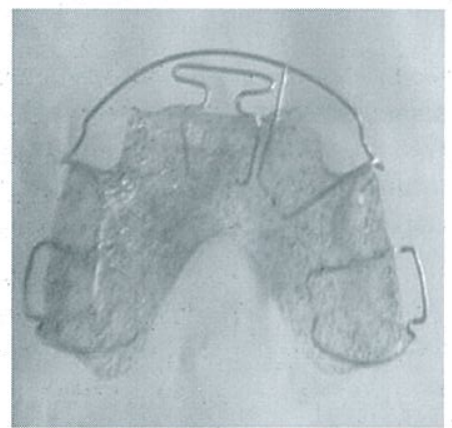

Gambar 6. Gambar alat ortodonsia lepasan untuk perawatan gigitan silang anterior dan palatoversi gigi 11 dan 22

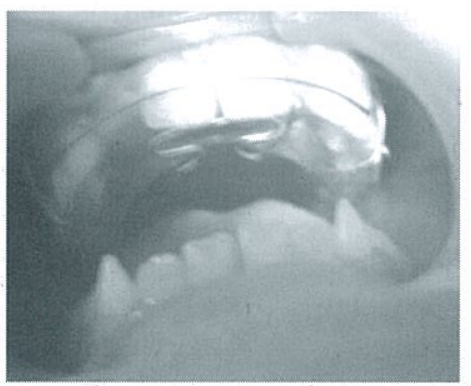

Gambar 7. Gambaran intra oral pasien pada kontrol tanggal 21 Februari 2006. Terlihat adanya al diastema sentral dan 12 sudah erupsi $1 / 3$ insisal

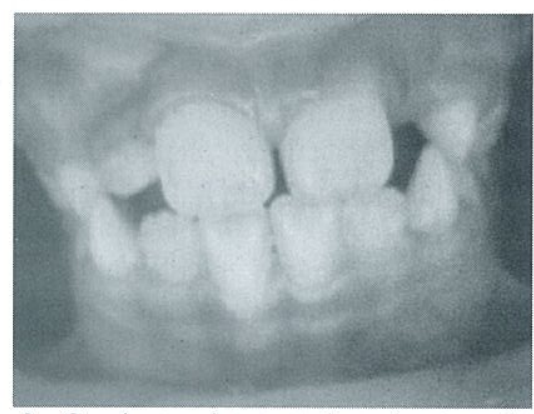

Gambar 8. Gambaran intra oral pasien pada kontrol tanggal 5 April 2006. Terlihat gigitan silang insisif sentral sudah terkoreksi.

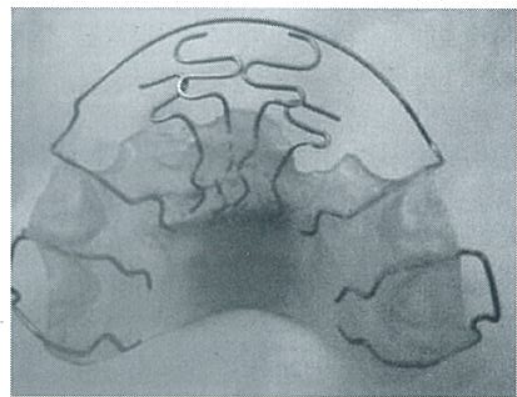

Gambar 9. Reparasi alat ortodonsia lepasan yang patah dengan penambahan simple finger spring 11 , 21 dan simple spring 12, 22.

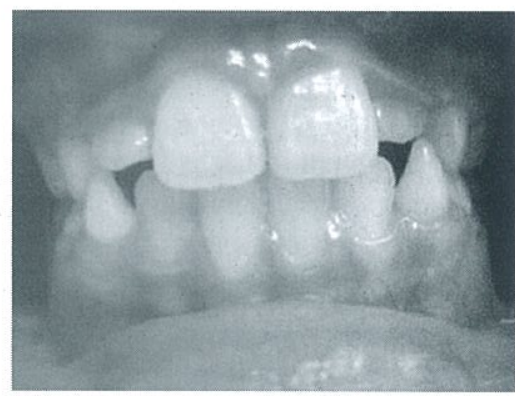

Gambar 10. Gambaran intra oral pasien tanggal 24 November 2006

Pada kontrol tanggal 12 Oktober 2005 dan kontrol selanjutnya dilakukan penggantian rubber elastis. Pada kunjungan tanggal 4 Januari 2006 diastema sentral sudah terkoreksi (Gambar 5), dan selanjutnya tanggal 20 Januari 2006 dilakukan insersi alat ortodonsia lepasan untuk mengoreksi gigitan silang anterior (Gambar 6). Pada pasien dan orang tua dijelaskan cara pemakaian alat ortodonsia lepasan.

Pada kontrol tanggal 21 Februari 2006, terlihat masih adanya diastema di antara gigi insisif sentral karena pasien jarang memakai alat ortodonsia lepasan (Gambar 7). Instruksi tentang pemakaian 
alat ortodonsia kembali diberikan kepada pasien dan orang tua. Pada kontrol tanggal 5 April 2006 terlihat gigitan silang anterior sudah terkoreksi, tetapi dijumpai malposisi 12 yang sedang erupsi yakni palatoversi dan 22 belum erupsi (Gambar 8). Karena itu pemakaian alat ortodonsia lepasan tidak dihentikan.

Pada kunjungan tanggal 8 September 2006, pasien datang dengan alat ortodonsia lepasan patah, 22 sudah erupsi $1 / 3$ insisal dan posisi 22 palatoversi. Dilakukan reparasi alat ortodonsia dengan penambahan simple finger spring pada 11, 21 dan simple spring pada 12, 22 (Gambar 9). Pada kontrol tanggal 24 November 2006 terlihat diastema antara insisif sentral sudah terkoreksi tetapi gigitan silang 12 dan 22 belum terkoreksi sehingga pemakaian alat ortodonsia lepasan dilanjutkan (Gambar 10).

\section{Pembahasan}

Pada kasus ini ditemukan mesiodens yang erupsi, berbentuk konis, di antara gigi insisif sentral kiri dan kanan rahang atas yang menyebabkan estetis tidak baik dan susunan gigi geligi tidak teratur serta menghalangi erupsi gigi insisif lateral rahang atas. Ini sesuai dengan literatur yang menyebutkan bahwa jika mesiodens erupsi dapat menyebabkan komplikasi seperti susunan gigi geligi yang tidak semestinya dan menimbulkan masalah estetika, erupsi terlambat dari gigi yang berdekatan serta penyimpangan arah erupsi gigi tetap pengganti. ${ }^{16}$

Penatalaksanaan mesiodens penting dilakukan secara dini, agar memberikan hasil yang optimal. Perawatan mesiodens pada kasus ini adalah dengan melakukan pencabutan mesiodens dan mengoreksi diastema di antara gigi insisif sentral dengan alat ortodonsia sederhana. Hal ini sesuai dengan literatur yang menyebutkan bahwa pencabutan mesiodens gigi sulung yang tidak erupsi atau mesiodens gigi tetap yang erupsi dianjurkan selama gigi geligi bercampur agar gigi insisif tetap dapat erupsi secara normal di dalam rongga mulut. ${ }^{2}$

Koreksi diastema setelah pencabutan mesiodens dilakukan dengan alat cekat sederhana, yakni pemasangan braket pada gigi-gigi insisif sentral dan menggerakkan gigi-gigi insisif sentral ini ke mesial dengan menggunakan rubber elastis dengan kekuatan ringan. Dalam literatur disebutkan bahwa pada beberapa kasus, perawatan ortodonsia cekat mungkin dibutuhkan untuk menyediakan ruangan yang cukup dalam lengkung rahang sebelum gigi- gigi insisif erupsi dan menempati tempat yang semestinya. ${ }^{4}$ Pemakaian alat cekat sederhana dalam hal ini harus dilakukan dengan hati-hati karena jika apeks gigi masih terbuka lebar, kemungkinan dapat mengganggu perkembangan akar gigi tersebut. ${ }^{17}$

Pada pasien ini kurang lebih 6 bulan setelah diastema anterior terkoreksi, gigi insisif lateral telah bererupsi spontan. Menurut literatur, $75 \%$ kasus dengan pencabutan mesiodens selama masa gigi bercampur menghasilkan erupsi spontan gigi yang berdekatan. Pengambilan secara bedah mungkin diperlukan untuk membantu gigi yang berdekatan erupsi, jika gigi tersebut tidak erupsi dalam waktu 612 bulan setelah tersedianya ruangan untuk gigi tersebut erupsi. ${ }^{2,4}$

Koreksi gigitan silang anterior pada pasien ini dilakukan dengan menggunakan alat ortodonsia lepasan, dan terlihat adanya relaps diastema di antara gigi insisif sentral selama perawatan karena pasien jarang memakai alat ortodonsia lepasan. Dalam hal ini terlihat pentingnya kerjasama pasien dan orang tua untuk keberhasilan perawatan.

\section{Kesimpulan}

Perawatan mesiodens berupa pencabutan mesio-dens serta penutupan diastema dan koreksi gigitan silang anterior dengan alat ortodonsia sederhana. Penutupan diastema diperoleh kurang lebih 3 bulan dengan alat cekat sederhana, sedangkan koreksi gigitan silang anterior gigi insisif sentral diperoleh setelah $2 \frac{1}{2}$ bulan pemakaian alat ortodonsia lepasan. Gigi insisif lateral kanan erupsi spontan kurang lebih 1 bulan setelah diastema anterior terkoreksi sedangkan gigi insisif lateral kiri erupsi kurang lebih 6 bulan setelah diastema anterior terkoreksi. Kerjasama pasien dan orang tua sangat diperlukan untuk keberhasilan perawatan.

\section{Daftar Acuan}

1. Schuurs AHB, Moorer WR, Prahl-Andersen B, Thoden Van Velzen SK, Visser JB. Patologi Gigi Geligi: Kelainan-kelainan Jaringan Keras Gigi. Alih Bahasa: Suryo S, Abyono R. Yogyakarta: UGM Press. 1992;16: 18-9, 22-4.

2. Anonymous. Clinical Guideline on Pediatric Oral Surgery. Council of Clinical affairs. 2005. Diakses dari: http://www.aapd.org/media/policiesguedelines /G Oral Surgery.pdf. Diakses 14 September 2005

3. Pinkham JR. Pediatric Dentistry. $3^{\text {th }}$ ed. Philadelphia: WB. Saunders Company. 1999: 43-4. 
4. Russell KA, Folwarczna MA. Mesiodens - Diagnosis and Management of Common Supernumerary Tooth. $J$ Can Dent Assoc 2003; 69(6): 362-6.

5. Budnick SD. Handbook of Pediatric Oral Pathology. London: Years Book Medical Publishers, INC. 1981: 73.

6. Regezi JA, Sciubba JJ, Jordan RCK. Oral Pathology. Clinical Pathologic Correlation. $4^{\text {th }}$ ed. San Francisco: Saunders. 1999: 373 - 4.

7. Garvey MT, Barry HJ, Blake M. Supernumerary Teeth -An Overview of Classification, Diagnosis and Management. Can Dent Assoc 1999; 65: 612-6.

8. Andlaw RJ, Rock WP. A Manual of Paediatric Dentistry. $4^{\text {th }}$ ed. London: Churchill Livingstone. 1996: 156.

9. McCoy JD, Shepard EE. Applied Orthodontics. $7^{\text {th }}$ ed. Philadelphia: Lea and Febriger. 1956: 81.

10. Stewart RE, Barber TK, Troutman KC, Wei SHY. Pediatric Dentistry SciencificFoundation and Clinical Practice. London: Mosby Company. 1982: 92 - 4.

11. Razdan A, Kapoor DN, Sharma VP, Tandon P. Supernumerary Central Incisors: An Overview and Management. Indian Orthodontic Society Journal Online November 2002. Diakses dari: http:/www. netodontist.com/projects/iosonline/ ios/ journal/ contents.htm. Diakses tanggal 30 Juni 2006.
12. Mc.Callum CA Jr. Oral Surgery for Children. In Finn SB. Clinical Pedodontics. $4^{\text {th }}$ ed. Philadelphia: W.B. Saunders Company.1973: $402-3$.

13. Debjit.R, Bhattacharya B, Sarkar S, Das G. Erupted Maxillary Conical Mesiodens in Deciduous Dentition in a Bengali girl - A case report. $J$ Indian Soc Pedo Prev Dent 2005; 23(1): 153 - 5.

14. Rajab LD, Hamdan MAM. Supernumerary teeth: Review of the Literature and Survey of 153 Cases. Int fPediatric Dentistry. 2002; 12: 244-54.

15. Wei SHY. Pediatric Dentistry: Total Patient Care. Philadelphia: Lea \& Febriger. 1988: 344-5, 467.

16. McDonald RE, Avery DR, Dean J.A. Dentistry for the Child and Adolescent. $8^{\text {th }}$ ed. St. Louis: Mosby. 2004: $665-6,668$.

17. Graber TM. Orthodontics Principles and Practice. Philadelphia: WB Saunders Co. 1966: 326-7, 332, 680.

18. Nakata M, Wei SHY. Occlusal Guidance in Pediatric Dentistry. Tokyo: Ishiyaku EuroAmerica, Inc. 1988: 26, 93.

19. Koch G, Modeér T, Poulsen S, Rasmussen P. Pediatric Dentistry - a Clinica Approach. Copenhagen: Blackwell Munksgaard. 1991: 259.

20. Cameron AC, Widmer RP.Handbook of Pediatric Dentistry. $2^{\text {nd }}$ ed. Philadelphia: Mosby. 2003: 193, 195. 